\title{
INFORMATION THEORY APPLIED TO PERCEPTUAL RESEARCH INVOLVING ART STIMULI
}

\section{Kerry Freedman}

The contents of this paper are a discussion of the utilization of information theory in discovering information about aesthetic behavior. The sense in which aesthetic behavior will be referred to in this context is in terms of apprehension of aesthetic stimuli, rather than the production of art objects. In looking at this topic, consideration of this sense of behavior assumes that the apprehension of aesthetic stimuli is an active rather than a passive state, and that behavior is examined in the overt responses of subjects involved in research based on information theory perspectives, where collected data is used to infer about this aesthetic apprehension and the behavior or others.

There are two fundamental ways that information theory based investigations have led to a further understanding of aesthetic behavior. The first is that through the development of information theory, a metric has been provided that enables researchers to study the effects of independent stimulus dimensions thought to be aesthetic on the responses of viewers. The use of information theory in this context is not primarily concerned with internal processes.

The second way information theory has enabled further understanding of aesthetic behavior is that it has led to the field of informationprocessing. This utilization has caused researchers to theorize about cognitive processes which are basic to concept formation resulting in the study of areas such as visual search (Neisser, 1963) and memory search (Sternberg, 1966).

An information-processing approach to research in aesthetics can be useful in three ways. First, as mentioned, it enables the systematic dissection of aesthetic stimulus dimensions in order to study their effects on the human system. Second, this perspective forces the realization that processing of an aesthetic object is a temporal experience that may be directed in a sequential manner by channels that influence the processing of information gained from these dimensions. Third, this theory enables the experiencing of an aesthetic object to be seen in terms of stages of processing that, although they are considered separable time intervals, are interacting and influence the resulting aesthetic behavior.

The history of information theory is relevant here because it has gone through some definitive changes that have affected the study of perception. Near the end of World War II, Weiner (1948) published a book on cybernetics. This view that there are similarities between biological and mechanical control systems was a fundamental seed in the development of the use of information theory in psychology (Simon, 1981).

The technological events that led to the use of information theory in studies of perception and behavior were two major theoretical contri- 
butions to the ongoing cybernetic perspective. One important event was the universal communication theory and re-definition of information devised by C. E. Shannon (Shannon \& Weaver, 1949). This communication theory provided a model that involved limited capacity channels over which messages were transmitted. The second occurence that forced the development of information theory was the advent of analog digital computers. Because of their apparent simulation of human cognitive processes, theorists saw in computers the potential for studying human information processing.

There have been a number of criticisms of the use of information theory in the study of perception (cf. Green \& Courtis, 1969). One of the major concerns has been the early definition of information by Shannon. This definition dealt only in terms of the uncertainty of physical dimensions of the message, not in terms of the receiver of the message. However, this early definition of information is considered by many to be outdated, and a new view of information has evorved.

Some of the seminal publications that have aided in the theoretical development of psychological research utilizing information theory have included: G. A. Miller's (1956) and W. R. Garner's (1962) reviews of research, F. Attneave's (1959) book, Applications of Information Theory to Psychology, the work of C. Cherry (1953) and D. E. Broadbent (1958, 1971) in dichotic listening and selective attention, and Sperling's analysis of iconic, short term and long term memory. The revivial of $F$. C. Donder's subtractive reaction time methods, work by Posner and Mitchell (1967) on matching by visual features versus matching by name, and finally, Tanner and Swet's (1954) explanation of Signal Dection Theory have further impacted the development of the use of information theory in studies of perception and have influenced the shifting meaning of information.

The perspective that information theory can be used to investigate aesthetic response is the basis for an influential body of works by $D$. E. Berlyne and his students and colleagues (Berlyne, 1977, 1974; Day, 1981). Berlyne was a classical Hullian behaviorist (Furedy \& Furedy, 1981) and combined these two theoretical approaches to study the effects of structional aesthetic stimulus dimensions on behavior.

Although Berlyne and his associates have done much through the use of information theory to discover aspects of aesthetic behavior, two concerns must be mentioned. The first was raised by Heckhausen (1964), that very simply, the long term phenomenal effect of Berlyne's stimuli may not be in accordance with its information-theoretic analys is of complexity. Heckhausen believed that length of viewing time and viewing situation influence "complexity as perceived" (p. 168).

The second concern is that Berlyne's behavioralist tradition views internal events in terms of associationistic correspondence assumptions. Although not of the most strict behavioral beliefs, for he has made inferences as to some of the interior events resulting from behavioral responses to stimuli, Berlyne's view is that the human nervous system is wired such that a one-to-one correspondence is caused by particular stimulus 
dimensions, rather than considering the process as being cognitively ongoing and interactive. It seems probable that there is not such a correspondence between the stimulus dimensions of a work of art and Berlyne's hypothetical neural system when considerations of learned concepts, such as values, are seen in their relation to perceived pleasantness or unpleasantness.

The study of human information processing is now included in the theory of cognitive psychology. It has become a conjunctive derivative of information theory available for use in the study of aesthetic behavior. In some respects, it is a revival of the initial historical topics of psychology, but with an alternative methodology. An important part of that methodology is seen through the use of computer based vocabulary and flow diagrams in the explanation of the processing of information by humans. Although these relatively linear, two-dimensional representations are realized to be overly simplistic attempts to understand the processing of human functioning, two positive aspects of the development of this approach, as mentioned earlier, are illustrated: (a) perception and higher processing such as attention and memory is temporal and occurs in stages or levels that have unity and interact; (b) processing is 7 imited by the capapcity of the channel that selectively handles information that changes during recoding. The connections between these processing components and the changes that occur as information is recoded are probably the central concern of information-processing research.

When confronted with an aesthetic object, we detect and integrate features of the object attended to in terms of their relevancy in memory. These physical features are parts of larger structural dimensions, such as collative properties, that can be measured through levels of uncertainty. Uncertainty, since it involves the human functions of prediction, has also to do with interior structural formations, such as concepts and images, which are retained relative to their interactive character. Further, these aspects of information-processing may change as development occurs.

The information-processing approach has been criticized for being too much concerned with the atomization of our perceptions in restrictive laboratory situations that have limited reference to the real world, and being too little concerned with the acquisition of meaning. It is true, that we generally do not see things in terms of patches of color or shapes, although that is how the information reaches our retinas. Rather, we very quickly interpret those sensations, whenever possible matching them to a prototypical mental structure in abstract memory. However, it is possible that developing information-processing theory may help provide a "methodology which adequately considers the interactive nature of aesthetic object and aesthetic response" (Crozier, 1981, p. 433). Some students of Berlyne feel that his approach falls short of considering this interactive aspect.

Already an indication of the transition toward studying functions of meaning has begun. Posner (1978) has suggested that looking at processing in regards to levels would be more appropriate than to refer 
to it simply in terms of stages. Research by Garner, Podgorny, and Frasca (1982) has shown support for this conceptualization. Their studies indicate that cognitive dimensions (such as familiarity) may override physical dimensions and may be used to sort stimuli even when cognitive dimensions conflict. These results indicate that functional roles of dimensions may be processed in parallel after initial processing of physical features. These studies and others show possible views of processing mechanisms that handle aesthetic dimensions such as referents to style, and cognitive dimensions such as preference and value in parallel, which could be useful in the study of aesthetic behavior.

\section{REFERENCES}

Attneave, F. Some informational aspects of visual perception. Psychological Review, 1954, 61, 183-193.

Berlyne, D. E. Aesthetics and psychobiology. New York: Appleton, 1971.

Berlyne, D. E. (Ed.). Studies in the new experimental aesthetics. Washington, D.C.: Hemisphere Publishing Corporation, 1974.

Broadbent, D. E. Perception and communication. New York: Pergamon, 1958.

Cherry, E. C. Some experiments on the recognition of speech, with one and with two ears. Journal of the Acoustical Society of America, $1953,25,925-979$.

Crozier, J. B. Information theory and melodic perception: In search of the aesthetic engram. In H. I. Day (Ed.), Advances in intrinsic motivation and aesthetics. New York: Plenum Press, 1981.

Day, H. I. (Ed.). Advances in intrinsic motivation and aesthetics. New York: PTenum Press, 1981.

Furedy, J. J. , \& Furedy, C. P. "My first interest is interest": Berlyne as an exemplar of the curiosity drive. In H. I. Day (Ed.), Advances in intrinsic motivation arld aesthetics. New York: Plenum Press, 1981.

Garner, W. R. Uncertainty and structure as psychological concepts. New York: Wiley, 1962.

Garner, W. R., Podgorny, P., \& Frasca, E. M. Physical and cognitive dimensions in stimulus comparison. Perception and Psychophysics $1982,31(6), 507-522$.

Green, R. T., \& Courtis, M.C. Information theory and figure perception: The metaphor that failed. In J. Hogg (Ed.), Psychology and the visual arts. Baltimore: Penguin Books, 1969.

Heckhausen, H. Complexity in perception: Phenomenal criteria and information theoretic calculus--A note on D. E. Berlyne's 'complexity effects'. Canandian Journal of Psychology, 1964, 18 (2), 168-173.

Miller, G. A. The magic number seven, plus or minus two. Psychological Review, 1956, 63, 81-97.

Neissen, U. VisuaT search. Scientific American, 1963, 210, 94-102.

Posner, M. I. Chronometric exploration of mind. Hillsdale, N.J.: Erlbaum, $197 \overline{8}$.

Posner, M. I., \& Mitchel, R. F. Chronometric analysis of classification. Psychological Review, 1967, 74, 392-409.

Shannon, C. E., \& Weaver, W. The mathematical theory of communication. Urbana: University of Illinois Press, 1949. 
Simon, H. A. The sciences of the artificial (2nd ed.). Cambridge, Mass.: The MIT Press, 1987.

Sternberg, S. High-speed scanning in human memory. Science, 1966, 153, $652-654$.

Tanner, W. P., \& Swets, J. A decision-making theory of visual detection. Psychological Review, 1954, 61, 401-409.

Weiner, N. Cybernetics. New York: Wiley, 1948. 